\title{
Endoscopic intragastric balloon: a gimmick or a viable option for obesity?
}

\author{
Katja Susanne Claudia Gollisch, Dirk Raddatz
}

Department of Gastroenterology and Gastrointestinal Oncology, Endocrine Unit, University Medical Center Göttingen, Göttingen, Germany Contributions: (I) Conception and design: All authors; (II) Administrative support: All authors; (III) Provision of study materials or patients: None; (IV) Collection and assembly of data: None; (V) Data analysis and interpretation: None; (VI) Manuscript writing: All authors; (VII) Final approval of manuscript: All authors.

Correspondence to: Prof. Dr. Dirk Raddatz. Department of Gastroenterology and Gastrointestinal Oncology, Endocrine Unit, University Medical Center Göttingen, Robert-Koch-Str. 40, 37075 Göttingen, Germany. Email: draddatz@med.uni-goettingen.de.

\begin{abstract}
Worldwide, the prevalence of obesity has doubled since 1980 in 70 countries. More than one in three adults now suffer from overweight or obesity. Health problems related to obesity include orthopedic problems, psychiatric conditions, metabolic and cardiovascular diseases, and of increasing concern, cancer. Thus, obesity has an enormous impact on the individual's wellbeing as well as on society's workforce and health care expenses. Medical efforts are ongoing to find safe and effective treatment options for obesity and its metabolic implications. At present, available treatment options include lifestyle interventions, pharmacotherapy, endoscopic applications, and bariatric surgery. Within the range of endoscopic treatment options, the intragastric balloon is the most widely used device. The idea is simple: the gastric volume is reduced by a balloon that is in most cases implanted by an endoscopic procedure similar to a gastroscopy. During the past decades, different models have been developed, which we will briefly introduce in this review. We aim at reviewing the pathophysiology underlying the effect of endoscopic intragastric balloon on weight loss and metabolic changes. We will assess expected short-term and long-term benefits for the patient, and we will discuss common side effects as well as rare complications. We will compare endoscopic intragastric balloon to conservative treatment options with or without pharmacological support on the one hand and to the spectrum of bariatric surgery on the other hand. In most patients, obesity must be considered a chronic disease that requires a lifelong treatment concept. In view of current treatment options for obesity, we will discuss whether endoscopic intragastric balloon is a viable treatment option, and who may be the right patient to benefit from it.
\end{abstract}

Keywords: Bariatric surgery; metabolic endoscopy; gastric balloon; obesity

Submitted Jun 26, 2019. Accepted for publication Sep 09, 2019.

doi: $10.21037 /$ atm.2019.09.67

View this article at: http://dx.doi.org/10.21037/atm.2019.09.67

\section{Introduction}

The intragastric balloon (IGB) probably set the starting point of endoscopic bariatric therapy. Depending on the system, an empty balloon is introduced into the stomach by means of a gastroscopy or by just swallowing a capsule. The balloon is then inflated with air or saline to varying volumes. This reduces the stomach volume, resulting in a feeling of satiety which shall then lead to weight loss. The treatment is limited to 6 months for most systems. Ideally the procedure is imbedded in a continuous weight loss program, and the patient is supported by an interdisciplinary team of healthcare professionals.

The idea of today's IGB systems may date back to as early as 1939 , when Michael DeBakey analyzed cases of gastric bezoars and concretions to find that $38 \%$ of the patients experienced weight loss. However, the vast majority of the patients suffered from nausea and vomiting even 
Table 1 Overview of FDA approved and/or CE certified intragastric balloons in alphabetic order

\begin{tabular}{|c|c|c|c|c|c|c|c|c|c|}
\hline Balloon type & Implant/explant & FDA approved & CE mark & Time in situ (months) & Filling & Volume $(\mathrm{mL})$ & TBWL (\%) & EWL (\%) & Ref. \\
\hline End-Ball $^{\circledR}$ & Endo/endo & No & Yes & 6 & Liquid/gas & 700 & 17.1 & 36.5 & (5) \\
\hline Heliosphere ${ }^{\circledR}$ BAG & Endo/endo & No & Yes & 6 & Air & 700 & 13.4 & 33.2 & (6) \\
\hline Lexbal $^{\circledR}$ & Endo/endo & No & Yes & 6 & Liquid & $500-800$ & 14.9 & 26.8 & (7) \\
\hline Obalon $^{\circledR}$ & Swallow/endo & Yes & Yes & 6 & Gas & $3 \times 250$ & 7.1 & $\mathrm{n} / \mathrm{a}$ & (9) \\
\hline Orbera $^{\circledR}$ & Endo/endo & Yes & Yes & 6 & Liquid & $400-700$ & 10.2 & 26.5 & (10) \\
\hline Reshape $^{\circledR}$ & Endo/endo & Yes & Yes & 6 & Liquid & $750-900$ & 6.8 & 25.1 & (11) \\
\hline Spatz3 $^{\circledR}$ & Endo/endo & No & Yes & 12 & Liquid & Adjustable & 20.1 & 45.8 & (12) \\
\hline
\end{tabular}

*, in progress. FDA, Food and Drug Administration; CE, Communauté Européenne; TBWL, total body weight loss; EWL, excess weight loss; endo, endoscopically; n/a, not applicable.

without necessarily losing weight (1). The first IGB, the "Garren-Edwards Gastric Bubble" was introduced in 1985 and experienced a similar problem. The FDA approved the system, but it was withdrawn after seven years because of major side effects, including gastric erosions, gastric ulcers, small bowel obstruction, and Mallory-Weiss tears, as well as insufficient efficacy on weight loss (2). Despite these first disappointing experiences, other systems have been developed and successfully introduced on the European and US American market: The Orber ${ }^{\circledR}$ Intragastric Balloon System (Apollo Endosurgery Inc, Austin, TX, United States, formerly BIB), was approved for use in Europe in 1997 and culminated in an FDA approval in 2015. It is the system, among all balloon systems, for which most scientific data on efficacy and safety are available; thus, it may be the most widely implanted system worldwide. Since 2015, another two balloon systems have gained FDA approval: The ReShape ${ }^{\circledR}$ Integrated Dual BalloonSystem (ReShape Medical, Inc., San Clemente, CA, United States), and the Obalon $^{\circledR}$ (Obalon Therapeutics, Inc.), the first swallowable balloon system that allows up to three balloons to be put in place without endoscopy. Removal of the Obalon ${ }^{\circledR}$ balloon system, however, also requires endoscopy. Finally, there is a number of Communauté Européenne (CE) approved but not yet U.S. food and drug administration (FDA) approved balloon systems under clinical investigation. Within these systems, the Spatz $3^{\circledR}$ intragastric balloon (Spatz FGIA Inc.) differs from the other balloons as it is adjustable and can stay in place for 12 months. The Elipse ${ }^{\circledR}$ Balloon (Allurion Technologies) is the only swallowable CE approved system that is removed by natural excretion and thus, ideally does not require any endoscopic procedure (3). An overview of FDA and CE approved IGBs is given in Table 1.

The idea of the IGB keeps being attractive: in contrast to bariatric surgery, the therapy is little or non-invasive, reversible and limited to a specified timeframe. However, the effect on weight loss is by far not comparable to what can be expected from operative procedures. As with any medical therapy decision, advantages and disadvantages must be weighed up to best support the patient.

\section{Pathophysiology}

It appears common-sense that a stomach that is continuously "pre-filled" by a rather large balloon will lead to an increased sensation of satiety and to reduced appetite. But which pathophysiological mechanisms may be underlying, and can the IGB indeed take advantage of these mechanisms?

Satiety and bodyweight are regulated by a complex neuro-humoral network which is, in part, represented in the gut brain axis. The current and highly accepted concept describes humoral and nerval afferences from adipose tissue and gut that are integrated in brain stem circuits. These brain stem circuits in turn provide hunger, saturation and satiety signals. The system is fed by mechanical stimuli such as stomach distension, and it is modulated by hormonal factors as well as by psychological factors, known for example as the reward system (13-15). Distension of the stomach in response to a meal signals saturation via parasympathetic afferents. Conversely, brain stem nuclei control the pre-prandial tonus and relaxation after a meal (13-15). Interestingly, functional neuro imaging studies 
have shown that there is a difference between balloon distension of the stomach and the physiological distension by nutrients: the pure mechanic distension by an inflated balloon addresses pain-processing brain region. This socalled "visceral pain neuromatrix" has been shown to be downregulated during nutrient infusion, which may constitute a necessity to ensure adequate food intake despite gastric distension (16). Considering this mechanism, pure gastric distension by an IGB without simultaneous food intake explains side effects in the first days after implantation and satiety after food reconstitution. However, there are limitations to this effect: functional MRI studies have shown that sweet beverages led to no significant effect on cortical brain circuits associated with food craving (17). Thus, Patients with an increased intake of liquid calories may not benefit from an IGB system.

On the humoral side, the satiety hormone, ghrelin, a 28 amino acid peptide expressed in the gastric fundus, is a major player in weight regulation (18). Its role in ballooninduced weight loss, however, is not clear $(19,20)$. Ly et al. show that the mechanical effects of balloon inflation alone did not reduce plasma ghrelin levels, so that caloric intake seems a mandatory signal for ghrelin induced sensation of satiety (21). Still, ghrelin levels decreased during IGB treatment and positively correlated with weight loss, suggesting that food-induced ghrelin is active in regulating satiety and possibly weight loss in the presence of IGB (22).

Besides gastric distension and humoral factors, gastric emptying represents another important mechanism to induce weight loss following IGB insertion. Thus, three months after balloon placement, solid and liquid scintigraphic gastric emptying time significantly slowed down, which correlated positively with weight loss (23). Despite these findings, there are data questioning whether the initial effects of IGB persist during the time of treatment. While subjective rating of hunger and food desire decreases shortly after IGB placement, these alterations disappear in the same subjects two months after IGB placement (24).

To sum up, gastric distension, ghrelin signaling, and gastric emptying are probably the major players involved in weight loss during IGB treatment. The extent to which each factor is involved can be modulated by the amount and form of caloric intake and by the time since the placement of the gastric balloon.

\section{Short- and long-term weight reduction}

In patients who had no previous bariatric interventions and in whom IGB was the primary weight-loss agent, short-term weight reduction as reported after six months treatment averaged at $11.5 \mathrm{~kg}$ and was more pronounced in subjects with higher BMI (25).

A recent meta-analysis performed by the American Society for Gastrointestinal Endoscopy Bariatric (ASGE) Endoscopy Task Force indicates that the Orbera ${ }^{\circledR}$ IGB leads to an overall pooled total body weight loss (TBWL) of $13.16 \%$ after 6 months. Furthermore, in three randomized controlled trials, excess weight loss (\%EWL) over controls was $26.9 \%$. Thus Orbera ${ }^{\circledR}$ meets the "preservation and incorporation of valuable endoscopic innovations" (PIVI) thresholds for obesity therapy which are set at 5\% TBWL and $15 \%$ EWL over control, respectively $(26,27)$.

Considering that intensive lifestyle intervention programs report a weight loss of 7-10 kg after 6 months, the effect of IGB therapy has to be considered "modest". While behavioral therapy still results in long-term weight loss of approximately $5 \mathrm{~kg}$, few long-term data are available after IGB therapy (28). Long-term follow up after IGB therapy is extremely heterogenic: a number of patients benefit from repeated use of the same endoscopic therapy, others seek medical therapy, and others decide on bariatric surgery during follow up. In one study, 100 patients who initially lost a mean of $12.6 \mathrm{~kg}$ with IGB therapy regained $6.5 \mathrm{~kg}$ during 2 years of follow-up, which compares well to other forms of weight loss strategies that are timely restricted (29). Tate et al. review controlled studies of the three FDA approved balloon systems, ReShape ${ }^{\circledR}$, Orbera ${ }^{\circledR}$ and Obalon ${ }^{\circledR}$ to conclude that all systems have comparable effects on weight loss. In summary, the effects were greater than control, smaller than bariatric surgery, but also smaller than the FDA approved weight loss drug, Qsymia (30). As mentioned before, gastric emptying time has been reported as a possible predictor for IGB success. Therefore, the combination of IGB with a medication that reduces gastric motility may potentiate the effect on weight loss $(31,32)$. Another predictor for successful treatment might be the extent of overweight. In non-obese but overweight patients, IGB successfully reversed diabetes and hypertension in a significant amount. EWL was up to $59 \%$ at 6 months and $29 \%$ at 3 years (33). Similarly, Jamal et al. report a better performance in overweight and obese patients with a BMI of $27.5-35 \mathrm{~kg} / \mathrm{m}^{2}$ compared to patients with higher BMIs (34).

\section{Adverse events}

Adverse events after IGB placement are common and 
similarly seen with all systems that are currently used. The rate of adverse events reported in single studies varies extremely depending on the focus of the study. It is clear, however, that the majority of patients carrying a gastric balloon suffer from nausea and vomiting. Metaanalyses report that $23 \%$ to $72 \%$ of the patients experience nausea and $20 \%$ to $50 \%$ of gastric balloon carriers report abdominal pain $(25,35,36)$. It is notable that even severe adverse events occurred frequently: the FDA pivotal trial for the most frequently used gastric balloon, Orbera ${ }^{\circledR}$, report gastric ulceration in $10 \%$ of the participants. Patients carrying ReShape ${ }^{\circledR}$ experienced gastric ulceration even in $35 \%$ of the cases probably due to high filling volumes of up to $900 \mathrm{~mL}(11,27)$. However, a large systematic review including 26 studies, mostly case series, reports gastric ulceration in only $0.3 \%$. Other rare severe complications following gastric balloon include intestinal obstruction $(0.8 \%)$, gastric perforation $(0.1 \%)$ and death $(0.05 \%)(25)$. Many patients tend to tolerate gastrointestinal side effects to the benefit of weight loss. Early removal of IGBs was reported in $3.5 \%$ to $7 \%$ of the patients $(25,26)$. Interestingly, the tolerability but also the effectiveness of IGB depends upon localization with more side effects and more weight loss with an antral position (37). The Spatz ${ }^{\circledR}$ Adjustable Balloon was developed to overcome tolerability issues by allowing to adjust the balloon's volume according to side effects and weight loss goals. However, a casecontrol study found no differences in side effects and weight loss outcome compared to Orbera ${ }^{\circledR}$ (38), and another study raised concerns regarding long-term safety (39). Single studies suggest, that air-filled balloons like the Heliosphere ${ }^{\circledR}$ BAG (Heliscopie, Vienne, France) or Obalon ${ }^{\circledR}$ will prevent nausea and vomiting while being also efficient in terms of weight loss $(6,9)$. This is remarkable since early airfilled balloons were removed from the market because of ineffectiveness and safety issues. Whether the newer generations have overcome these problems still needs to be answered by head-to-head studies with fluid-filled balloons. In order to prevent or overcome nausea and vomiting, patients receive antiemetic treatment after IGB placement on a regular basis. Prospective studies have shown serotonin receptor antagonists to be effective, and even more so, if combined with midazolam $(40,41)$.

\section{Comparison to surgery and drugs}

Very obese patients are often recommended to undergo bariatric surgery as the most effective way to achieve significant weight loss. The IGB and laparoscopic vertical sleeve gastrectomy are based on the same idea of reducing the stomach volume to induce weight loss. This raises the question in how far these procedures are comparable mechanistically. The average gastric volume is about 1,200 $\mathrm{mL}$. In obesity, this volume can reach up to the threefold size. A successful weight reduction after sleeve gastrectomy does not correlate with the extent of the absolute volume reduction, but with the residual volume, whereby a residual volume of more than $100 \mathrm{~mL}$ is associated with a poorer outcome $(42,43)$. The IGB, at a filling volume of $600 \mathrm{~mL}$, would leave a residual volume of $600 \mathrm{~mL}$ in a normal weight person and much more in an obese or very obese person. Thus, the restrictive characteristics of the surgical and the endoscopic procedures differ tremendously, which explains the much weaker effect of the IGB. The great difference in residual gastric volume may also explain that humoral effects with reduced ghrelin and increased GLP-1 release are seen in sleeve gastrectomy but not in IGB $(44,45)$. When translated into weight loss, the endoscopic therapy as a single treatment stands far behind surgical methods. Bariatric surgery initially achieves an exceptional weight loss of up to $31 \%$ depending on the type of surgery. After 10 years of follow up, patients remain a $29 \%$ weight reduction compared to baseline (46). Available data on long term weight loss after gastric balloon therapy show modest results with substantial regain of weight after balloon removal if no other therapies follow. Profound metabolic improvements are routinely seen following bariatric surgery. Metabolic data following IGB placement report only limited success that does not go beyond what could be achieved with a conservative therapy for weight reduction (47). In view of these facts, it seems plausible that some medical treatment options are superior to the IGB in respect of metabolic improvements. The GLP1 agonist, liraglutide, leads to weight loss and can stop the progression of pre-diabetes into diabetes over a relatively long period of 3 years (48). Semaglutide, which recently received FDA approval as an antidiabetic drug, seems even more potent reaching a TBWL of $13.8 \%$ after 1 year (49), and a novel combination drug of GLP and GIP receptor agonists proved still more effective. The combination drug has been tested in a phase 2 trial, where $73 \%$ of the patients reached the weight loss goal of $5 \%$ compared to $22 \%$ in the dulaglutide group and $0 \%$ in the placebo group (50). In conclusion, when compared to surgery or medical therapy, bariatric surgery will lead to a much more profound weight loss than IGB treatment, combined with clear metabolic 
benefits. Medical treatment may be similarly effective as IGB in inducing weight loss; however, differences will be seen depending on patient characteristics and choice of drug. In respect of metabolic effects, antidiabetic drugs based on GLP-1 and GIP related pathways promise to be more effective than the IGB, while the side effects nausea and vomiting are probably equally frequent.

\section{Special indications}

In view of the wide spectrum of available weight reduction interventions, the question arises, for which patients the IGB may represent the optimal solution. There are no comprehensive studies available on this topic. Reviewing the literature, however, brings up groups of patients who may specifically benefit from IGB treatment. As described before, some data suggest that the greatest effects on weight loss are achieved in overweight and moderately obese patients (34). This patient group, especially if metabolically healthy, will not qualify for bariatric surgery. The IGB can support weight loss and give a "kick-start" to successful weight loss, especially in situations where life style interventions were unsuccessful (51). In line with this theory, follow-up studies have shown successful weight maintenance after balloon removal mainly in the lower BMI groups $(5,34,52)$.

On the other side of the obesity spectrum, IGB therapy has been discussed in a preoperative setting: in superobese it is reasonable to reduce body weight before bariatric surgery in order to improve associated comorbidities, to facilitate surgery by reducing liver volume and intraabdominal fat and to finally reduce complications. In fact, a 14-day very lowcalorie diet was shown to reduce postoperative complication rate (53). Similar results could be presumed following IGB treatment. However, Coffin et al. show in a multicenter prospective study that while IGB induced preoperative weight loss, neither complication rate nor postoperative weight loss was influenced (54). Thus, pretreatment with IGB before bariatric surgery does reduce body weight but has so far not been proven to be beneficial for surgery outcomes (54-56). Another subgroup which has been studied for pre-surgical IGB treatment are obese patients awaiting kidney transplantation, as $\mathrm{BMI}>35 \mathrm{~kg} / \mathrm{m}^{2}$ can preclude renal insufficient patients from being waitlisted (57) or put them at greater risk for complications after transplantation (58). IGB therapy resulted in weight loss in these patients and proved to be save. However, the study was too small to conclude on benefits regarding kidney transplantation after
IGB treatment (58).

While transplant patients surely are a minority within the obese population, children and adolescents represent a growing proportion of the obesity community. It is important to understand whether the IGB may be a worthy treatment option for younger patients. Numerous studies have shown that the benefits of conservative therapy for adolescents are very limited (59). Although more and more adolescents undergo surgical measures, they are considered to be the last resort. Long-term data on success and side effects of bariatric surgery in children and adolescents do not exist, and it is known that children and adolescents often times fail to take their supplement on a regular basis. Consequently, these patients are prone for deficiency symptoms after a few years. In face of this problem, the effects of gastric banding as a potentially reversible intervention has recently been studied in adolescents (60). Reversibility can also be argued as an advantage of the IGB. While there is little data on the use of a gastric balloon in adolescents, the available studies show that the procedure can be used safely and effectively (61-63). However, it needs to be emphasized that none of the balloons has to date been approved for use in minors. Their use is therefore currently only possible within the framework of studies.

In search of the "ideal patient" for IGB treatment one can sum up that lower BMI patients $\left(25-35 \mathrm{~kg} / \mathrm{m}^{2}\right)$ may experience more profound and longer lasting benefits on weight loss than more obese patients; however, data are diverse on this issue $(26,34)$. In very obese patients, IGB treatment has been proven effective and safe in preoperative settings. However, available data fail to prove benefits as to the post-operative outcomes in these patients compared to patients who have not received IGB treatment.

\section{Conclusions}

After 35 years of experience with IGB systems in the spectrum of anti-obesity therapies, the concept has not found its position as a standard therapy for weight reduction. A number of meta-analyses have summed up weight benefits and side effect of IGB therapy, coming to the conclusion, that weight reduction is moderate and side effects are common, including severe but seldom complications such as gastric ulceration and intestinal obstruction. In addition, metabolic benefits are only seen after sufficient weight loss, clearly putting the IGB behind bariatric surgery but also behind drug interventions that involve the GLP-1 or GIP system. As a complement to life style interventions the IGB 
may have its place as it facilitates initial weight loss and thus may increase the patient's motivation to continue life style efforts. In this setting, IGB therapy shows the best results in overweight and moderately obese patients, which is in our eyes the main indication for this therapy. When we talk about "moderate weight effects" which are comparable to conservative treatment effects, we need to consider that in most studies mean TBWL\% and standard deviation (SD) is given rather than ranges. This kind of data does not transparently show the large range of success and does not reveal what is maximally achievable given the right balloon and patient. For example, a $30 \mathrm{~kg}$ TBWL is a realistic goal with IGB treatment in selected subjects and could turn a $120 \mathrm{~kg}$ obese individual into an overweight or even normalweight $90 \mathrm{~kg}$ person. The answer to the question, whether the IGB is a useful tool, will finally reflect perspectives and expectations. IGB therapy is not a magic bullet that leads to long-term remissions from obesity in most cases. Such expectations would certainly be presumptuous. IGB is a tool for selected patients that can be part of a lifelong obesity therapy. In the ideal case, the IGB helps patients so that an initial weight reduction positively influences lifestyle changes that will then allow weight stabilization in the long term. Even failure of the IGB therapy may have a benefit if it strengthens the patient's insight that conservative methods are not the key to success and thus pave the way for metabolic surgery. It is accepted that effectiveness of IGB therapy will never reach that of bariatric surgery and in clinical practice IGB therapy will not be considered a true alternative to surgical procedures. The success of IGB therapy must be measured against conservative therapy programs and drugs. The individual preference will depend on multiple factors, including the patient's choice, local conditions and funding agencies.

Looking at alternative therapies, other endoscopic procedures are evolving that appear to be more effective in the metabolic respect: the duodenal-jejunal bypass sleeve mimics the situation after Y-roux bypass surgery by bypassing the duodenal mucosa. Despite beneficial effects on glycemic control and body weight $(64,65)$, the $\mathrm{CE}$ Certificate of conformity was withdrawn in 2017 due to a deficient quality management system. The results of a new pivotal trial will decide on a comeback of the device (47). An innovative procedure that pursues reprogramming of neuroendocrine cells of the duodenum is the duodenal mucosal resurfacing with promising preliminary data $(66,67)$. Finally, Endoscopic sleeve gastroplasty, as a minimally invasive procedure to reduce gastric volume, also seems to be more effective than IGB therapy (68). Thus, further endoscopic procedures may be promising future options for weight loss and metabolic improvement in obesity.

Now we come back to the initial question, whether or not endoscopic IGB therapy is a gimmick. "Gimmick" is defined as "something that is not serious or of real value that is used to attract people's attention or interest temporarily, especially to make them buy something" (69). If you take a significant reduction of body weight as a "real value", the benefit of the IGB is more than zero. IGB therapy consistently led to a reduction of the body weight of approx. 5\% when compared to a control as shown in meta-analyses, thus meeting the criteria for a successful weight loss therapy (26). Therefore, IGB therapy has a value, albeit moderate and depending on the right patient choice. A certain advertising effect, however, can probably not be denied for IGB systems. The concept of restricting the gastric volume is easy to understand and might lead to expectations that will not be met in many cases. On the other hand, the low invasive procedure may suggest lower rates of side effects than we see in reality. Thus, it is the physician's responsibility to choose the right patient and to well explain benefits and side effects that can be expected. If this is done, IGB treatment ends up not to be a gimmick but a viable option for the selected patient and under the right conditions.

\section{Acknowledgments}

Funding: None.

\section{Footnote}

Provenance and Peer Review: This article was commissioned by the Guest Editor (Muhammed Ashraf Memon) for the focused issue "Bariatric Surgery" published in Annals of Translational Medicine. The article was sent for external peer review organized by the Guest Editor and the editorial office.

Conflicts of Interest: The focused issue "Bariatric Surgery" was commissioned by the editorial office without any funding or sponsorship. MAM served as the unpaid Guest Editor of the focused issue. The other authors have no conflicts of interest to declare.

Ethical Statement: The authors are accountable for all 
aspects of the work in ensuring that questions related to the accuracy or integrity of any part of the work are appropriately investigated and resolved.

Open Access Statement: This is an Open Access article distributed in accordance with the Creative Commons Attribution-NonCommercial-NoDerivs 4.0 International License (CC BY-NC-ND 4.0), which permits the noncommercial replication and distribution of the article with the strict proviso that no changes or edits are made and the original work is properly cited (including links to both the formal publication through the relevant DOI and the license). See: https://creativecommons.org/licenses/by-nc-nd/4.0/.

\section{References}

1. DeBakey M, Ochsner A. Bezoars and concretions: A comprehensive review of the literature with an analysis of 303 collected cases and a presentation of 8 additional cases. Surgery 1939;5:132-60.

2. Benjamin SB, Maher KA, Cattau EL, Jr., et al. Doubleblind controlled trial of the Garren-Edwards gastric bubble: an adjunctive treatment for exogenous obesity. Gastroenterology 1988;95:581-8.

3. Choi SJ, Choi HS. Various Intragastric Balloons Under Clinical Investigation. Clin Endosc 2018;51:407-15.

4. Machytka E, Gaur S, Chuttani R, et al. Elipse, the first procedureless gastric balloon for weight loss: a prospective, observational, open-label, multicenter study. Endoscopy 2017;49:154-60.

5. Keren D, Rainis T. Intragastric Balloons for Overweight Populations-1 Year Post Removal. Obes Surg 2018;28:2368-73.

6. Lecumberri E, Krekshi W, Matia P, et al. Effectiveness and safety of air-filled balloon Heliosphere BAG(R) in 82 consecutive obese patients. Obes Surg 2011;21:1508-12.

7. Zurawinski W, Sokolowski D, Krupa-Kotara K, et al. Evaluation of the results of treatment of morbid obesity by the endoscopic intragastric balloon implantation method. Wideochir Inne Tech Maloinwazyjne 2017;12:37-48.

8. Almeghaiseeb ES, Ashraf MF, Alamro RA, et al. Efficacy of intragastric balloon on weight reduction: Saudi perspective. World J Clin Cases 2017;5:140-7.

9. Sullivan S, Swain J, Woodman G, et al. Randomized shamcontrolled trial of the 6-month swallowable gas-filled intragastric balloon system for weight loss. Surg Obes Relat Dis 2018;14:1876-89.

10. Courcoulas A, Abu Dayyeh BK, Eaton L, et al.
Intragastric balloon as an adjunct to lifestyle intervention: a randomized controlled trial. Int J Obes (Lond) 2017;41:427-33.

11. Ponce J, Woodman G, Swain J, et al. The REDUCE pivotal trial: a prospective, randomized controlled pivotal trial of a dual intragastric balloon for the treatment of obesity. Surg Obes Relat Dis 2015;11:874-81.

12. Usuy E, Brooks J. Response Rates with the Spatz3 Adjustable Balloon. Obes Surg 2018;28:1271-6.

13. Amin T, Mercer JG. Hunger and Satiety Mechanisms and Their Potential Exploitation in the Regulation of Food Intake. Curr Obes Rep 2016;5:106-12.

14. Hussain SS, Bloom SR. The regulation of food intake by the gut-brain axis: implications for obesity. Int $\mathrm{J}$ Obes (Lond) 2013;37:625-33.

15. Acosta A, Camilleri M, Shin A, et al. Quantitative gastrointestinal and psychological traits associated with obesity and response to weight-loss therapy. Gastroenterology 2015;148:537-46.e4.

16. Coen SJ. When pain and hunger collide; psychological influences on differences in brain activity during physiological and non-physiological gastric distension. Neurogastroenterol Motil 2011;23:485-9.

17. Stopyra MA, Friederich HC, Sailer S, et al. The effect of intestinal glucose load on neural regulation of food craving. Nutr Neurosci 2019. [Epub ahead of print].

18. Buzga M, Evzen M, Pavel K, et al. Effects of the intragastric balloon MedSil on weight loss, fat tissue, lipid metabolism, and hormones involved in energy balance. Obes Surg 2014;24:909-15.

19. Mani BK, Zigman JM. Ghrelin as a Survival Hormone. Trends Endocrinol Metab 2017;28:843-54.

20. Dos-Santos RC, Reis LC, Perello M, et al. The actions of ghrelin in the paraventricular nucleus: energy balance and neuroendocrine implications. Ann N Y Acad Sci 2019;1455:81-97.

21. Ly HG, Dupont P, Van Laere K, et al. Differential brain responses to gradual intragastric nutrient infusion and gastric balloon distension: A role for gut peptides? Neuroimage 2017;144:101-12.

22. Mion F, Napoleon B, Roman S, et al. Effects of intragastric balloon on gastric emptying and plasma ghrelin levels in non-morbid obese patients. Obes Surg 2005;15:510-6.

23. Layec S, Val-Laillet D, Heresbach D, et al. Gastric tone, volume and emptying after implantation of an intragastric balloon for weight control. Neurogastroenterol Motil 2010;22:1016-21, e265-6.

24. Pasquali R, Besteghi L, Casimirri F, et al. Mechanisms 
of action of the intragastric balloon in obesity: effects on hunger and satiety. Appetite 1990;15:3-11.

25. Yorke E, Switzer NJ, Reso A, et al. Intragastric Balloon for Management of Severe Obesity: a Systematic Review. Obes Surg 2016;26:2248-54.

26. Abu Dayyeh BK, Kumar N, Edmundowicz SA, et al. ASGE Bariatric Endoscopy Task Force systematic review and meta-analysis assessing the ASGE PIVI thresholds for adopting endoscopic bariatric therapies. Gastrointest Endosc 2015;82:425-38.e5.

27. Abu Dayyeh BK, Eaton LL, Woodman G, et al. A Randomized, Multi-Center Study to Evaluate the Safety and Effectiveness of an Intragastric Balloon As an Adjunct to a Behavioral Modification Program, in Comparison With a Behavioral Modification Program Alone in the Weight Management of Obese Subjects. Gastrointestinal Endoscopy 2015;81:AB147.

28. Bray GA, Heisel WE, Afshin A, et al. The Science of Obesity Management: An Endocrine Society Scientific Statement. Endocr Rev 2018;39:79-132.

29. Dastis NS, Francois E, Deviere J, et al. Intragastric balloon for weight loss: results in 100 individuals followed for at least 2.5 years. Endoscopy 2009;41:575-80.

30. Tate CM, Geliebter A. Intragastric Balloon Treatment for Obesity: Review of Recent Studies. Adv Ther 2017;34:1859-75.

31. Su HJ, Kao CH, Chen WC, et al. Effect of intragastric balloon on gastric emptying time in humans for weight control. Clin Nucl Med 2013;38:863-8.

32. Gomez V, Woodman G, Abu Dayyeh BK. Delayed gastric emptying as a proposed mechanism of action during intragastric balloon therapy: Results of a prospective study. Obesity (Silver Spring) 2016;24:1849-53.

33. Genco A, Lopez-Nava G, Wahlen C, et al. Multicentre European experience with intragastric balloon in overweight populations: 13 years of experience. Obes Surg 2013;23:515-21.

34. Jamal MH, Almutairi R, Elabd R, et al. The Safety and Efficacy of Procedureless Gastric Balloon: a Study Examining the Effect of Elipse Intragastric Balloon Safety, Short and Medium Term Effects on Weight Loss with 1-Year Follow-Up Post-removal. Obes Surg 2019;29:1236-41.

35. Trang J, Lee SS, Miller A, et al. Incidence of nausea and vomiting after intragastric balloon placement in bariatric patients - A systematic review and meta-analysis. Int J Surg 2018;57:22-9.

36. Zheng Y, Wang M, He S, et al. Short-term effects of intragastric balloon in association with conservative therapy on weight loss: a meta-analysis. J Transl Med 2015;13:246.

37. Papavramidis TS, Grosomanidis V, Papakostas P, et al. Intragastric balloon fundal or antral position affects weight loss and tolerability. Obes Surg 2012;22:904-9.

38. Russo T, Aprea G, Formisano C, et al. BioEnterics Intragastric Balloon (BIB) versus Spatz Adjustable Balloon System (ABS): Our experience in the elderly. Int J Surg 2017;38:138-40.

39. Daniel F, Abou Fadel C, Houmani Z, et al. Spatz 3 Adjustable Intragastric Balloon: Long-Term Safety Concerns. Obes Surg 2016;26:159-60.

40. Abdelhamid SA, Kamel MS. A prospective controlled study to assess the antiemetic effect of midazolam following intragastric balloon insertion. J Anaesthesiol Clin Pharmacol 2014;30:383-6.

41. Van Hee R, Van Wiemeersch S, Lasters B, et al. Use of anti-emetics after intragastric balloon placement: experience with three different drug treatments. Obes Surg 2003;13:932-7.

42. Elbanna H, Emile S, El-Hawary GE, et al. Assessment of the Correlation Between Preoperative and Immediate Postoperative Gastric Volume and Weight Loss After Sleeve Gastrectomy Using Computed Tomography Volumetry. World J Surg 2019;43:199-206.

43. Hanssen A, Plotnikov S, Acosta G, et al. 3D Volumetry and its Correlation Between Postoperative Gastric Volume and Excess Weight Loss After Sleeve Gastrectomy. Obes Surg 2018;28:775-80.

44. Sista F, Abruzzese V, Clementi M, et al. Effect of Resected Gastric Volume on Ghrelin and GLP-1 Plasma Levels: a Prospective Study. J Gastrointest Surg 2016;20:1931-41.

45. Evers SS, Lewis AG, Tong C, et al. The Unconventional Role for Gastric Volume in the Response to Bariatric Surgery for Both Weight Loss and Glucose Lowering. Ann Surg 2019. [Epub ahead of print].

46. Maciejewski ML, Arterburn DE, Van Scoyoc L, et al. Bariatric Surgery and Long-term Durability of Weight Loss. JAMA Surg 2016;151:1046-55.

47. Raddatz D. Metabolic Endoscopy: Development and Perspectives. Digestion 2019. [Epub ahead of print].

48. le Roux CW, Astrup A, Fujioka K, et al. 3 years of liraglutide versus placebo for type 2 diabetes risk reduction and weight management in individuals with prediabetes: a randomised, double-blind trial. Lancet 2017;389:1399-409.

49. O'Neil PM, Birkenfeld AL, McGowan B, et al. Efficacy 
and safety of semaglutide compared with liraglutide and placebo for weight loss in patients with obesity: a randomised, double-blind, placebo and active controlled, dose-ranging, phase 2 trial. Lancet 2018;392:637-49.

50. Frias JP, Nauck MA, Van J, et al. Efficacy and safety of LY3298176, a novel dual GIP and GLP-1 receptor agonist, in patients with type 2 diabetes: a randomised, placebocontrolled and active comparator-controlled phase 2 trial. Lancet 2018;392:2180-93.

51. Ashrafian H, Monnich M, Braby TS, et al. Intragastric balloon outcomes in super-obesity: a 16-year city center hospital series. Surgery for obesity and related diseases: official journal of the American Society for Bariatric Surgery 2018;14:1691-9.

52. Dogan UB, Gumurdulu Y, Akin MS, et al. Five percent weight lost in the first month of intragastric balloon treatment may be a predictor for long-term weight maintenance. Obes Surg 2013;23:892-6.

53. Van Nieuwenhove Y, Dambrauskas Z, Campillo-Soto A, et al. Preoperative very low-calorie diet and operative outcome after laparoscopic gastric bypass: a randomized multicenter study. Arch Surg 2011;146:1300-5.

54. Coffin B, Maunoury V, Pattou F, et al. Impact of Intragastric Balloon Before Laparoscopic Gastric Bypass on Patients with Super Obesity: a Randomized Multicenter Study. Obes Surg 2017;27:902-9.

55. Ball W, Raza SS, Loy J, et al. Effectiveness of Intra-Gastric Balloon as a Bridge to Definitive Surgery in the Super Obese. Obes Surg 2019;29:1932-6.

56. Leeman MF, Ward C, Duxbury M, et al. The intra-gastric balloon for pre-operative weight loss in bariatric surgery: is it worthwhile? Obes Surg 2013;23:1262-5.

57. Holley JL, Monaghan J, Byer B, et al. An examination of the renal transplant evaluation process focusing on cost and the reasons for patient exclusion. Am J Kidney Dis 1998;32:567-74.

58. Beaudreuil S, Iglicki F, Ledoux S, et al. Efficacy and Safety of Intra-gastric Balloon Placement in Dialyzed Patients Awaiting Kidney Transplantation. Obes Surg 2019;29:713-20.

59. Kumar S, Kelly AS. Review of Childhood Obesity: From Epidemiology, Etiology, and Comorbidities to

Cite this article as: Gollisch KS, Raddatz D. Endoscopic intragastric balloon: a gimmick or a viable option for obesity? Ann Transl Med 2020;8(Suppl 1):S8. doi: 10.21037/ atm.2019.09.67
Clinical Assessment and Treatment. Mayo Clin Proc 2017;92:251-65.

60. Roebroek YGM, Paulus GF, van Mil E, et al. Bariatric surgery in adolescents: a prospective randomized controlled trial comparing laparoscopic gastric banding to combined lifestyle interventions in adolescents with severe obesity (BASIC trial). BMC Pediatr 2019;19:34.

61. Fittipaldi-Fernandez RJ, Guedes MR, Galvao Neto MP, et al. Efficacy of Intragastric Balloon Treatment for Adolescent Obesity. Obes Surg 2017;27:2546-51.

62. Reece LJ, Sachdev P, Copeland RJ, et al. Intra-gastric balloon as an adjunct to lifestyle support in severely obese adolescents; impact on weight, physical activity, cardiorespiratory fitness and psychosocial well-being. Int J Obes (Lond) 2017;41:591-7.

63. De Peppo F, Caccamo R, Adorisio O, et al. The Obalon swallowable intragastric balloon in pediatric and adolescent morbid obesity. Endosc Int Open 2017;5:E59-63.

64. Riedel N, Laubner K, Lautenbach A, et al. Trends in BMI, Glycemic Control and Obesity-Associated Comorbidities After Explantation of the Duodenal-Jejunal Bypass Liner (DJBL). Obes Surg 2018;28:2187-96.

65. Gollisch KS, Lindhorst A, Raddatz D. EndoBarrier Gastrointestinal Liner in Type 2 Diabetic Patients Improves Liver Fibrosis as Assessed by Liver Elastography. Exp Clin Endocrinol Diabetes 2017;125:116-21.

66. Haidry RJ, van Baar AC, Galvao Neto MP, et al. Duodenal mucosal resurfacing: proof-of-concept, procedural development, and initial implementation in the clinical setting. Gastrointest Endosc 2019;90:673-681.e2.

67. Rajagopalan H, Cherrington AD, Thompson CC, et al. Endoscopic Duodenal Mucosal Resurfacing for the Treatment of Type 2 Diabetes: 6-Month Interim Analysis From the First-in-Human Proof-of-Concept Study. Diabetes Care 2016;39:2254-61.

68. Fayad L, Cheskin LJ, Adam A, et al. Endoscopic sleeve gastroplasty versus intragastric balloon insertion: efficacy, durability, and safety. Endoscopy 2019;51:532-9.

69. Gimmick. In Cambridge Advanced Learner's Dictionary \& Thesaurus (Internet). Cambridge, UK. Available online: https://dictionary.cambridge.org/de/worterbuch/englisch/ gimmick 